Southern Illinois University Carbondale

OpenSIUC

Articles

Biochemistry \& Molecular Biology

$11-1-2016$

\title{
Observation on the ultrastructure morphology of HeLa cells treated with ethanol: Statistical analysis.
}

\author{
Fakhri Al-Bagdadi \\ Matthew J Young \\ James P Geaghan \\ Shaomian Yao \\ Humberto M Barona \\ See next page for additional authors
}

Follow this and additional works at: http://opensiuc.lib.siu.edu/bmb_articles

This is an Author's Accepted Manuscript of an article published in Ultrastructural pathology, Vol.40, No.6, 2016 (copyright Taylor \& Francis), available online at: http://www.tandfonline.com/[doi]

\section{Recommended Citation}

Al-Bagdadi, Fakhri, Young, Matthew J, Geaghan, James P, Yao, Shaomian, Barona, Humberto M, Martinez-Ceballos, Eduardo and Yoshimura, Masami. "Observation on the ultrastructure morphology of HeLa cells treated with ethanol: Statistical analysis.." Ultrastructural pathology 40, No. 6 (Nov 2016): 324-332. doi:10.1080/01913123.2016.1233160. 
Authors

Fakhri Al-Bagdadi, Matthew J Young, James P Geaghan, Shaomian Yao, Humberto M Barona, Eduardo Martinez-Ceballos, and Masami Yoshimura 
Observation on the ultrastructure morphology of HeLa cell treated with ethanol: statistical analysis.

Running Title: The effects of ethanol on HeLa cell ultrastructure

${\text { Fakhri Al-Bagdadi }{ }^{1 *} \text {, Matthew J. Young }}^{2 *}$, James P. Geaghan ${ }^{3}$, Shaomian Yao ${ }^{1}$, Humberto M. Barona $^{4}$, Eduardo Martinez-Ceballos ${ }^{5}$, and Masami Yoshimura ${ }^{1}$

${ }^{1}$ Department of Comparative Biomedical Sciences, Louisiana State University, School of Veterinary Medicine, Baton Rouge, LA 70803, USA.

${ }^{2}$ Department of Biochemistry and Molecular Biology, Southern Illinois University, School of Medicine, Carbondale, IL 62901, USA.

${ }^{3}$ Department of Experimental Statistics, Louisiana State University, Baton Rouge, LA 70803, USA.

${ }^{4}$ Department of Mathematics, Southern University and A\&M College, Baton Rouge, LA 70813, USA.

${ }^{5}$ Department of Biology, Southern University and A\&M College, Baton Rouge, LA 70813, USA.

*To whom correspondence may be addressed. Email: albagdadi@vetmed.lsu.edu or matthew.young@siu.edu 


\section{Summary}

It is estimated that $5.9 \%$ of all human deaths are attributable to alcohol consumption and that the harmful use of ethanol ranks among the top five risk factors for causing disease, disability, and death worldwide. Ethanol is known to disrupt phospholipid packing and promote membrane hemifusion at lipid bilayers. With the exception of mitochondria involved in hormone synthesis, the sterol content of mitochondrial membranes is low. As membranes that are low in cholesterol have increased membrane fluidity, and are the most easily disordered by ethanol, we hypothesize that mitochondria are sensitive targets for ethanol damage. HeLa cells were exposed to $50 \mathrm{mM}$ ethanol and the direct effects of ethanol on cellular ultrastructure were examined utilizing transmission electron microscopy. Our ultramicroscopic analysis revealed that cells exposed to ethanol harbor fewer incidence of apoptotic morphology; however, significant alterations to mitochondria and to nuclei occurred. We observed statistical increases in the amount of irregular cells and cells with multiple nuclei, nuclei harboring indentations, and nuclei with multiple nucleolus-like bodies. Indeed, our analysis revealed that mitochondrial damage is the most extensive type of cellular damage. Rupturing of cristae was the most prominent damage followed by mitochondrial swelling. Ethanol exposure also resulted in increased amounts of: mitochondrial rupturing, organelles with linked membranes, and mitochondria localizing to indentations of nuclear membranes. We theorize that these alterations could contribute to cellular defects in oxidative phosphorylation and, by extension, the inability to generate regular levels of cellular adenosine triphosphate.

Keywords: ethanol; mitochondria; nuclei; ultrastructure; transmission electron microscopy; HeLa 


\section{Introduction}

The World Health Organization estimates that $5.9 \%$ of all deaths are attributable to alcohol consumption and that harmful use of ethanol ranks among the top five risk factors for causing disease, disability, and death worldwide [1]. Of concern to cellular membranes, ethanol disrupts the packing of phospholipids and promotes membrane hemifusion, the joining of two leaflets of two adjacent membranes [2,3]. In general, the sterol content within mitochondrial membranes is low, except in those cells that biosynthesize hormones [4,5], and membranes that are low in cholesterol have increased membrane lipid fluidity and are more easily disordered by ethanol [2]. As mitochondrial lipid bilayers typically harbor the least amount of sterols, in comparison to other organelles [4], we predict that they are highly sensitive to ethanol damage. The mitochondrion is colloquially referred to as the powerhouse of the cell as this organelle is the site where oxidative phosphorylation (OXPHOS) occurs. OXPHOS is the process of coupling substrate oxidation to production of the energy-rich molecule adenosine triphosphate (ATP). In addition to contributing to energy production, mitochondria play important roles in the regulation of cell survival and cell death and have been implicated in carcinogenesis [6,7].

Tissue culture provides a valuable experimental tool to assess ethanol cytotoxicity and provides several experimental advantages over in vivo studies. First, cell lines grown in culture are generally homogeneous. Second, it is easy to distinguish the direct effects of ethanol on cultured cell lines without the effects of secondary humoral factors, such as cytokines [8]. Third, cell culture permits the investigator to easily visualize the subcellular effects of ethanol treatment utilizing electron microscopy. Cagnon and co-workers demonstrated that alcohol caused rupturing of mitochondrial cristae in mice prostate cells [9], while a chronic alcohol usage 
experiment utilizing Calomys callosus as a model system demonstrated mitochondrial cristae rupturing in palate mucous membrane cells [10]. Experiments exploiting the HeLa human cervical cancer cell line have investigated changes to mitochondrial ultrastructure on exposure to various insults and drugs such as: laser irradiation [11], the anticancer compounds zerumbone [12] and vinblastine [13], antibiotics such as toyocamycin [14] and chloramphenicol [15], and the phthalocyanine dyes [11]. Here we utilized HeLa cells to investigate the direct effects of ethanol on cellular ultrastructure using electron microscopy. A total of 1189 cells were examined in this study.

While electron microscopy is a powerful diagnostic tool to detect subcellular morphological abnormalities, which are undetectable by light microscopy [16], previous studies on the effects of ethanol on cellular ultrastructure have not provided sufficient statistical analyses. We carried out a comprehensive statistical analysis on the effect of alcohol on cellular ultrastructure utilizing high-resolution transmission electron microscopy. Although cells exposed to ethanol harbor fewer incidence of apoptotic morphology, there are significant alterations to mitochondria and to nuclei. We observed increases in the amount of irregular cells and cells with multiple nuclei, nuclei harboring indentations, and nuclei with multiple nucleoluslike bodies. Furthermore, our analysis revealed that mitochondrial damage is the most extensive type of cellular damage. Ruptured cristae were the most frequent damage followed by mitochondrial swelling. Ethanol exposure also resulted in increased amounts of: mitochondrial rupturing, organelles with linked membranes, and mitochondria localizing to indentations of the nuclear membrane. We theorize these alterations could contribute to cellular defects in OXPHOS and by extension the inability to generate regular levels of cellular ATP. 


\section{Materials and methods}

\subsection{Tissue culture}

HeLa cells were obtained from ATCC. Cells were incubated in a Sanyo Science incubator (Sanyo North America Corporation) using $225 \mathrm{~cm}^{2}$ flasks containing minimum essential medium with $10 \%$ fetal bovine serum, penicillin $(50 \mu \mathrm{g} / \mathrm{ml})$, streptomycin $(50 \mu \mathrm{g} / \mathrm{ml})$, and neomycin $(100 \mu \mathrm{g} / \mathrm{ml})$. The flasks were maintained in a humidified atmosphere of $95 \%$ air and $5 \% \mathrm{CO}_{2}$ at $37^{\circ} \mathrm{C}$.

\subsection{Ethanol treatment and sample preparation}

Cultures were exposed to ethanol by growing in $39 \mathrm{ml}$ minimum essential medium containing $50 \mathrm{mM}$ ethanol and incubated at $37^{\circ} \mathrm{C}$ for $24 \mathrm{~h}$. The next day the medium was aspirated out of the flasks and cells were then incubated in $10 \mathrm{ml}$ of PBS $\left(\mathrm{Ca}^{2+} \& \mathrm{Mg}^{2+}\right.$ free, obtained from Dulbecco) containing $0.04 \%$ EDTA for $5 \mathrm{~min}$. Cells were harvested off the bottom of the flask by scrapping and then the suspensions were transferred into microcentrifuge tubes, vortexed and centrifuged at $134 \mathrm{~g}$ for 5 minutes. Untreated control HeLa cells were harvested in parallel. The PBS was aspirated off the pellets and the cells were washed with ice cold $0.1 \mathrm{M} \mathrm{NaCac}$ buffer containing 5\% sucrose, vortexed for 1 - 2 minutes, centrifuged, and finally the buffer was aspirated. This step was repeated twice. The last buffer change was discarded and replaced with fixative of $1.25 \%$ Glutaraldehyde and $2 \%$ Formaldehyde in $0.1 \mathrm{M}$ $\mathrm{NaCac}$ buffer for 40 minutes on crushed ice. Next, the cells were dehydrated with various grades

of ethanol, the alcohol concentration was gradually increased from $50 \%, 70 \%, 80 \%, 90 \%$, to $100 \%$, then the samples were processed and embedded in araldite-epon capsules. Capsules were 
sectioned for electron microscopy. Thin sections of $70 \mathrm{~nm}$ were prepared using ultra microtome Leica EM uc7/Fc7-8/09 (Leica Microsystem, GmbH. Vienna, Austria).

\subsection{Transmission electron microscopy (TEM)}

Thin sections were impregnated with lead citrate and uranyl acetate and examined by JEOL-JEM-1011 Transmission Electron Microscope (JEOL LTD, 1-2 Musashino, 3-Chome, Akishima, Tokyo 196 Japan). The ultrastructure morphometric study was conducted on silver sections mounted on 300 mesh copper grids using the JEOL-JEM-1011 electron microscope operated at $80 \mathrm{kV}$. The silver sections were examined by discarding one-micron thick section between each mounted ribbon sections on a grid. Then another silver color ribbon was made from the next level of the same capsule. This process continued by examining a total of nine ribbon sections. The mounted grids were obtained from ten different levels of the same capsule, which allowed data collection from different HeLa cells.

\subsection{Data analysis}

Randomly examined cells in each view were captured by digital photography and images were saved for numerical and morphological data collection. The collected data include: shape and number of cells, shape and number of nuclei, shape and number of nucleoli, presence of cytoplasmic processes, shape and number of mitochondria in each cell, number of swollen (enlarged) and ruptured mitochondria, and the number of mitochondria with ruptured or distorted cristae, including their distribution within the mitochondrial matrix (Table 1). We examined 606 control cells and 583 cells exposed to ethanol. To test the differences between the proportions in 
each of the nine characteristics of HeLa cells in ethanol or control treatments, the following hypotheses were considered:

$$
\begin{aligned}
& H_{0}: p_{1}=p_{2} \\
& H_{1}: p_{1}>p_{2}
\end{aligned}
$$

where $p_{1}$ is the proportion or percentage of the characteristic in the ethanol treatment, and $p_{2}$ is the corresponding proportion in the control treatment. The following two statistical procedures were used in Excel 2010 Developer to test the hypotheses:

1. The Z-test statistic which uses the normal distribution at $\alpha=0.01$, with the following assumptions: 1) the two random samples must be independent of one another; 2) since the samples sizes are sufficiently large, both populations can be considered approximately normally distributed; 3) the sample proportion of a characteristic with the ethanol treatment is $\hat{p}_{1}=n_{1} / 583$, where $n_{1}$ is the cell count of the characteristic, and the correspondent sample proportion with the control treatment is $\hat{p}_{2}=n_{2} / 606$ and $\hat{p}=\frac{n_{1}+n_{2}}{1189}$. The formula for test statistic is $z=\frac{\left(\hat{p}_{1}-\hat{p}_{2}\right)}{\sqrt{\hat{p}(1-\hat{p})\left(\frac{1}{606}+\frac{1}{583}\right)}}$. If $z>z_{.01}=2.325$ then the null hypothesis, $H_{0}$, is rejected.

2. The P-value approach, in which the area of the right hand tail is computed by using the normal distribution value of the opposite of the $\mathrm{z}$ test statistic, P-value $=$ NORMSDIST(z). If P-value $<\alpha=0.01$ then the null hypothesis, $H_{0}$, is rejected.

The results obtained with Excell 10 were verified using Mathematica 10.4 (Wolfram Inc., Champaign, IL). 


\subsection{TEM assessment of cellular apoptotic morphology}

Cells with apoptotic morphology were assessed as previously described [12,17]. Briefly, TEM was used to take random digital pictures from HeLa capsule sections treated separately with and without alcohol. Data for each image was collected as described in section 2.4 above and standard ultrastructure criteria were utilized to define cells undergoing morphological changes consistent with apoptosis. The criteria used to define apoptotic morphology included: cell shrinkage, increased granularity, dense cytoplasm, tightly packed organelles, pyknosis (condensed chromatin), karyorrhexis (discontinuous and fragmented nuclear envelop), and formation of apoptotic bodies (irregular cell membrane and vesicles).

\section{Results}

\subsection{Assessment of untreated HeLa cell ultrastructure}

In HeLa control cells, nuclei appeared lucent with 1 - 3 nucleolus-like bodies and their mitochondria appeared densely stained, of similar size, and rounded. Mitochondria from control cells displayed normal morphological shapes and sizes with tightly packed cristae located within densely stained mitochondrial matrices (Figure 1 Panel 1 and Materials and methods). These

mitochondria were spread throughout the cytoplasm around the nucleus and very few showed rupturing of cristae.

\subsection{HeLa cells treated with ethanol harbor altered nuclear structures}

HeLa cells exposed to ethanol were observed to undergo apoptosis less frequently than untreated control cells (Table 1). Cell division was not significantly affected; however, in cells treated with ethanol, cellular apoptotic morphology decreased by $\sim 60 \%$ with respect to control 
cells and the occurrence of irregular cells increased $\sim 2.6$-fold (Odds Ratio, Table 1; Figure 2 and Materials and methods). In this study, apoptotic morphology was the only observed variable to have fewer instances with ethanol treatment: only $\sim 2.6 \%$ compared to $6.1 \%$ in the controls (Table 1). Cells treated with alcohol were irregular in shape and harbored altered nuclear and mitochondrial structures (Figure 1, compare panels 1 and 2). Ethanol treatment resulted in a 2.8fold increase in cells harboring multiple nuclei (Table 1, Figure 3). The nuclei were $\sim 2.5$ times more likely to harbor indentations and the occurrence of multiple densely stained nucleolus-like bodies increased 1.8-fold (Table 1; Figure 1 compare panel 1 with panels 2, 3, 4, and 6).

\subsection{HeLa cells treated with ethanol harbor altered mitochondrial structures}

In the samples obtained from ethanol treatment, the majority of the mitochondria were located to one side of the nucleus and some were larger than others (Figure 1, compare panel 1 with panels 2, 3, and 6). In contrast to the densely stained mitochondria from control cells, HeLa cells treated with ethanol harbor lucent or pale stained mitochondria of various irregular shapes and sizes that also typically appear extremely hypertrophied (Figure 1, compare panel 1 with panels 2 - 6). These swollen mitochondria contain less cristae that are oblique and disorganized (panels 4 and 5). Swollen mitochondria were $\sim 3.8$ times more likely to occur when HeLa cells were treated with ethanol (Table 1, Figure 4). Mitochondria with dense matrices were also observed in cells treated with ethanol, albeit not as often as in control cells (Figure 1, panel 2 6). In general, we observed that mitochondria from cells exposed to ethanol harbor less cristae and these cristae appeared distorted and ruptured. The effect of ethanol on mitochondrial cristae is depicted in Figure 5 at high magnification. The likelihood of ruptured mitochondria and ruptured cristae significantly increased by 2.1- and 4.2-fold, respectively (Figure 4). Also, we observed an increase in the amount of mitochondria with linked membranes and these structures 
could represent ethanol-induced membrane hemifusion or a disruption to the dynamic mitochondrial fusion and fission cycle, or both (Figure 1, panels 2 - 6). As depicted in Figure 1, mitochondria from cells exposed to ethanol were localized within nuclear membrane indentations (panels 2, 3, and 6), inside extensions of cytoplasmic cell processes (panel 2), and were abnormally long and appeared to fold over on themselves (compare panel 1 with panels 2 6). Ruptured mitochondria were observed in close proximity to nuclei (panels 2 and 3) and mitochondria with compromised outer membranes were also apparent (see HM in panels 4 and 5). In summary, partial cristolysis or rupturing of mitochondrial cristae, was the most frequent mitochondrial alteration we observed followed by mitochondrial swelling and rupturing of mitochondria (Table 1). The p-values for these observations were all less than 0.0001 indicating highly significant differences.

\section{Discussion}

Ethanol induces expansion of lipid membranes, decreases membrane thickness, and disorders lipid acyl chains [2,3]. We hypothesized that mitochondria are sensitive targets to ethanol damage due to their distinct two-membrane architecture harboring both an outer mitochondrial membrane and an inner mitochondrial membrane. In agreement with studies demonstrating that mitochondrial membranes harbor low levels of sterols [4,5], and observations that lipid membranes low in cholesterol are more easily disordered by ethanol [2], mitochondrial damage was the most frequent damage observed for HeLa cells exposed to ethanol. We examined the intracellular ultrastructure of 583 ethanol exposed and 606 untreated HeLa cells by high-resolution transmission electron microscopy. Cell division was not affected by alcohol treatment but cellular apoptotic morphology decreased 2-fold relative to untreated cells. Statistical analysis revealed that rupturing of mitochondrial cristae was the most extensive type 
of cellular damage caused by ethanol treatment followed by the occurrence of: swollen mitochondria, multiple nuclei, irregular shaped cells, nuclei harboring indentations, ruptured mitochondria, and multiple nucleolus-like bodies (Table 1). The distribution of organelles was affected with mitochondria localizing to nuclear indentations within the cytoplasm. Mitochondria of cells treated with ethanol appeared lucent or pale and were of various shapes and sizes with many of the organelles appearing extremely hypertrophied. We observed that cells treated with ethanol harbor mitochondria with a higher occurrence of linked membranes, which could represent ethanol-induced membrane hemifusion [2,3], or disruption to the mitochondrial dynamic cycle of fusion and fission, or both. Pathological mutations in genes responsible for mitochondrial fusion have been associated with alterations in the organization of mitochondrial networks and with the inhibition of energy metabolism [18,19]. Heterogeneous ultrastructure pathology may represent altered mitochondrial networks [7] and, according to Arismendi-Morillo, total or partial cristolysis may suggest severely compromised OXPHOS [20]. Furthermore, it is evident that there is a close relationship between mitochondrial energy production and the status of the mitochondrial reticulum in human cells [21].

According to Castro and coworkers [22], rat mammary tissues may bioactivate ethanol to become highly mutagenic [23] and to generate free radicals, leading to oxidative stress, which may play a role in tumor promotion $[24,25]$. Additionally, mitochondrial DNA is susceptible to ethanol-induced damage and if not repaired can impair mitochondrial function [26]. In regard to ethanol exposure and cancer, mitochondrial morphological alterations caused by ethanol have been reported in various tumors and malignancies such as carcinomas [27,28], Warthin's tumor [29], malignant glioma cells [30], cancer cell lines [31], and in clones of cancer cells with mitochondrial respiration defects [32]. Additionally, HeLa cells exposed to the 
chemotherapeutic agent cis-4-(((2-Chloroethyl)nitrosamino)carbonyl)amino)-cyclohexane carboxylic acid (cis-acid), caused mitochondrial swelling and vacuolation [33]. In spite of these advances, much more research is required to understand the potential implications of ethanol and other pharmaceuticals in relation to cancer cell bioenergetics, and specifically the bioenergetics of HeLa cells.

Mitochondria play a central role in the process of programmed cell death known as apoptosis, which can occur through intrinsic or extrinsic pathways [34], with the intrinsic apoptotic pathway being initiated by the mitochondrial permeability transition pore [34]. Upon induction of apoptosis, remodeling of cristae takes place to allow the release of an estimated $85 \%$ of cytochrome $\mathrm{c}$ that is stored within the intracristal space [35]. However, mitochondria are best known for their role in cellular energy production but they are also essential for diverse metabolic functions such as heat production, calcium and iron homeostasis as well as the biosynthesis of heme, pyrimidines, and steroids [34,36,37]. Mitochondria generate most of the cellular energy in the form of ATP via the electron transport chain and the oxygen-dependent pathway of OXPHOS [16,34]. In this regard, the mitochondrial swelling and distortion of cristae observed here was similar to that reported in human astrocytic tumors and malignant glioma cells associated with hypoxic-ischemic conditions [7,30]. Because it has been stated that mitochondrial defects play a significant role in the development and progression of cancer and are important in cancer therapy [7] exposure of human cells to agents that reduce mitochondrial OXPHOS could have broad implications on therapeutic approaches to treat cancer, as demonstrated by recent studies that employed mitochondrial-targeted anticancer agents $[38,39]$. Reactivation of apoptosis by rebooting mitochondria in cancer cells is currently a hot topic in cancer research. Interestingly, morphological changes in mitochondria are implicated in many 
aspects of altered metabolism in cancer cells [40] and cancer cell mitochondria are structurally and functionally different from wild-type mitochondria [41,42]. One example is in human lung adenocarcinoma cells that have faulty mitochondrial fusion and the mitochondrial dynamic cycle is shifted towards mitochondrial fission/fragmentation [43]. Our current knowledge of fragmented mitochondrial structure and alterations to mitochondrial metabolism in cancer cells offers the potential for mitochondria to be exploited as markers for early detection of cancer [42].

Down-regulation of the gene encoding the mitochondrial cristae morphology control protein mitofilin in HeLa cells results in abnormal mitochondrial ultrastructure and cell death [36]. In a study on the effect of alcohol on the hard palatine mucosa, Martinez and coworkers proposed that alcohol may target mitofilin resulting in altered mitochondria and ruptured cristae [10]. The alcohol exposed HeLa cells studied here displayed mitochondrial cristae variation similar to that reported for mouse mitofilin [36]. John and coworkers indicated that variation of the mitochondrial cristae architecture is ascribed to different metabolic states of the organelle [36].

We theorize that in HeLa cells treated with ethanol, OXPHOS is reduced due to structural alterations to the mitochondrion. Future studies could investigate mitochondrial bioenergetics in cells exposed to ethanol to assess mitochondrial damage. The morphological changes we observed when cells are exposed to $50 \mathrm{mM}$ ethanol agrees with in vivo impairment observed around the blood alcohol concentrations of 43 to $65 \mathrm{mM}$ [44]. From our TEM morphometric analysis we determined that multiple cellular irregularities in HeLa cells are caused by ethanol exposure; however, apoptotic morphology occurred less frequently. Future ethanol exposure studies utilizing models and/or cell lines representative of cancer, could investigate whether or not decreased apoptosis is a universal phenomenon. In addition to using TEM to assesse 
apoptotic morphology, cytochrome c released from mitochondria and caspase-3 activation could be investigated as markers of apoptosis.

\section{Conclusions}

The aim of this work was to analyze the effects of ethanol on mitochondrial ultrastructure in HeLa cells utilizing TEM. We determined that in HeLa cells treated with ethanol, significant alterations to mitochondria and to nuclei occur. Mitochondrial damage was the most extensive type of intracellular damage and cellular apoptotic morphology occurred less frequently.

\section{Acknowledgments}

This research was supported by National Institutes of Health Grant AA13148 (MY).

\section{References}

[1] Chestnov O, Saxena S, Fleischmann A, Poznyak V, Rekve D, Renström M, Clark N, Laatikainen L, Stevens G, Mathers C, et al.: Global status report on alcohol and health. Edited by Poznyak V, Rekve D. Geneva, Switzerland: Management of Substance Abuse Unit, Department of Mental Health and Substance Abuse, World Health Organization; 2014:378. Data WLC-i-P (Series Editor).

[2] Goldstein DB: Effect of alcohol on cellular membranes. Ann Emerg Med 1986, 15:10131018.

[3] Gurtovenko AA, Anwar J: Interaction of ethanol with biological membranes: the formation of non-bilayer structures within the membrane interior and their significance. J Phys Chem B 2009, 113:1983-1992.

[4] van Meer G, Voelker DR, Feigenson GW: Membrane lipids: where they are and how they behave. Nat Rev Mol Cell Biol 2008, 9:112-124.

[5] Satori CP, Henderson MM, Krautkramer EA, Kostal V, Distefano MD, Distefano MM, Arriaga EA: Bioanalysis of eukaryotic organelles. Chem Rev 2013, 113:2733-2811.

[6] Kroemer G, Galluzzi L, Brenner C: Mitochondrial membrane permeabilization in cell death. Physiol Rev 2007, 87:99-163. 
[7] Arismendi-Morillo GJ, Castellano-Ramirez AV: Ultrastructural mitochondrial pathology in human astrocytic tumors: potentials implications pro-therapeutics strategies. J Electron Microsc (Tokyo) 2008, 57:33-39.

[8] French SW: Mechanisms of alcoholic liver injury. Can J Gastroenterol 2000, 14:327-332.

[9] Cagnon VH, Tomazini FM, Garcia PJ, Martinez M, Padovani CR, Martinez FE: Structure and ultrastructure of the ventral prostate of isogenic mice $(\mathrm{C} 57 \mathrm{~B} 1 / 6 \mathrm{~J})$ submitted to chronic alcohol ingestion. Tissue Cell 2001, 33:354-360.

[10] Martinez M, Milton FA, de Oliveira SA, de Lima NF, Segatelli TM, Pinheiro PF, Almeida CC, Mello W, Quitete VH, Martinez FE: Ultrastructural changes on the hard palatine mucosa of Calomys callosus after 120 days of experimental chronic alcoholism. J Submicrosc Cytol Pathol 2005, 37:59-65.

[11] de Castro Pazos M, Pacheco-Soares C, Soares da Silva N, DaMatta RA, Pacheco MT: Ultrastructural effects of two phthalocyanines in CHO-K1 and HeLa cells after laser irradiation. Biocell 2003, 27:301-309.

[12] Abdel Wahab SI, Abdul AB, Alzubairi AS, Mohamed Elhassan M, Mohan S: In vitro ultramorphological assessment of apoptosis induced by zerumbone on (HeLa). J Biomed Biotechnol 2009, 2009:769568.

[13] Jordan MA, Thrower D, Wilson L: Effects of vinblastine, podophyllotoxin and nocodazole on mitotic spindles. Implications for the role of microtubule dynamics in mitosis. J Cell Sci 1992, 102 ( Pt 3):401-416.

[14] Heine U: Electron microscopic studies on HeLa cells exposed to the antibiotic toyocamycin. Cancer Res 1969, 29:1875-1880.

[15] Kislev N, Spolsky CM, Eisenstadt JM: Effect of chloramphenicol on the ultrastructure of mitochondria in sensitive and resistant strains of HeLa. J Cell Biol 1973, 57:571-579.

[16] Kyriacou K, Kyriakides T: Mitochondrial encephalomyopathies: a review of routine morphological diagnostic methods with emphasis on the role of electron microscopy. $\mathrm{J}$ Submicrosc Cytol Pathol 2006, 38:201-208.

[17] Doonan F, Cotter TG: Morphological assessment of apoptosis. Methods 2008, 44:200-204.

[18] Pich S, Bach D, Briones P, Liesa M, Camps M, Testar X, Palacín M, Zorzano A: The Charcot-Marie-Tooth type 2A gene product, Mfn2, up-regulates fuel oxidation through expression of OXPHOS system. Hum Mol Genet 2005, 14:1405-1415.

[19] Hoppins S, Nunnari J: The molecular mechanism of mitochondrial fusion. Biochim Biophys Acta 2009, 1793:20-26.

[20] Arismendi-Morillo G: Electron microscopy morphology of the mitochondrial network in gliomas and their vascular microenvironment. Biochim Biophys Acta 2011, 1807:602-608. 
[21] Benard G, Bellance N, James D, Parrone P, Fernandez H, Letellier T, Rossignol R: Mitochondrial bioenergetics and structural network organization. J Cell Sci 2007, 120:838848.

[22] Castro GD, de Castro CR, Maciel ME, Fanelli SL, de Ferreyra EC, Gómez MI, Castro JA: Ethanol-induced oxidative stress and acetaldehyde formation in rat mammary tissue: potential factors involved in alcohol drinking promotion of breast cancer. Toxicology 2006, 219:208-219.

[23] Dellarco VL: A mutagenicity assessment of acetaldehyde. Mutat Res 1988, 195:1-20.

[24] Hussain SP, Hofseth LJ, Harris CC: Radical causes of cancer. Nat Rev Cancer 2003, 3:276285.

[25] Castro JA, Castro GD: Mechanisms in prostate damage by alcohol. In Comprehensive Handbook of Alcohol Related Pathology. Edited by Preedy VR, Watson RR: Elsevier Science Ltd., Academic Press; 2004:1007-1015.

[26] Hoek JB, Cahill A, Pastorino JG: Alcohol and mitochondria: a dysfunctional relationship. Gastroenterology 2002, 122:2049-2063.

[27] Springer EL: Comparative study of the cytoplasmic organelles of epithelial cell lines derived from human carcinomas and nonmalignant tissues. Cancer Res 1980, 40:803-817.

[28] Cuezva JM, Krajewska M, de Heredia ML, Krajewski S, Santamaría G, Kim H, Zapata JM, Marusawa H, Chamorro M, Reed JC: The bioenergetic signature of cancer: a marker of tumor progression. Cancer Res 2002, 62:6674-6681.

[29] Kataoka R, Hyo Y, Hoshiya T, Miyahara H, Matsunaga T: Ultrastructural study of mitochondria in oncocytes. Ultrastruct Pathol 1991, 15:231-239.

[30] Steinbach JP, Wolburg H, Klumpp A, Probst H, Weller M: Hypoxia-induced cell death in human malignant glioma cells: energy deprivation promotes decoupling of mitochondrial cytochrome c release from caspase processing and necrotic cell death. Cell Death Differ 2003, 10:823-832.

[31] Rossignol R, Gilkerson R, Aggeler R, Yamagata K, Remington SJ, Capaldi RA: Energy substrate modulates mitochondrial structure and oxidative capacity in cancer cells. Cancer Res 2004, 64:985-993.

[32] Xu RH, Pelicano H, Zhou Y, Carew JS, Feng L, Bhalla KN, Keating MJ, Huang P: Inhibition of glycolysis in cancer cells: a novel strategy to overcome drug resistance associated with mitochondrial respiratory defect and hypoxia. Cancer Res 2005, 65:613-621.

[33] Al-Bader AA, Al-Zuhair AG, Ramadan AA, Mohammed ME: Ultrastructural changes in HeLa cells following treatment with the antineoplastic agent cis-acid. Oncology 1982, 39:242-249. 
[34] Wallace DC, Fan W, Procaccio V: Mitochondrial energetics and therapeutics. Annu Rev Pathol 2010, 5:297-348.

[35] Zick M, Rabl R, Reichert AS: Cristae formation-linking ultrastructure and function of mitochondria. Biochim Biophys Acta 2009, 1793:5-19.

[36] John GB, Shang Y, Li L, Renken C, Mannella CA, Selker JM, Rangell L, Bennett MJ, Zha J: The mitochondrial inner membrane protein mitofilin controls cristae morphology. Mol Biol Cell 2005, 16:1543-1554.

[37] Van Houten B, Woshner V, Santos JH: Role of mitochondrial DNA in toxic responses to oxidative stress. DNA Repair (Amst) 2006, 5:145-152.

[38] Fulda S, Galluzzi L, Kroemer G: Targeting mitochondria for cancer therapy. Nat Rev Drug Discov 2010, 9:447-464.

[39] Dumas J-F, et al.: Mitochondria and cancer. In Cellular Bioenergetics in Health and Diseases: New Perspectives in Mitochondrial Biology. Edited by Lou P-H, Petersen N: Research Signpost; 2012:115-147.

[40] Peluso G, Nicolai R, Reda E, Benatti P, Barbarisi A, Calvani M: Cancer and anticancer therapy-induced modifications on metabolism mediated by carnitine system. J Cell Physiol 2000, 182:339-350.

[41] Gogvadze V, Orrenius S, Zhivotovsky B: Mitochondria in cancer cells: what is so special about them? Trends Cell Biol 2008, 18:165-173.

[42] Modica-Napolitano JS, Singh KK: Mitochondria as targets for detection and treatment of cancer. Expert Rev Mol Med 2002, 4:1-19.

[43] Archer SL: Mitochondrial dynamics--mitochondrial fission and fusion in human diseases. N Engl J Med 2013, 369:2236-2251.

[44] Schuckit MA: Alcoholism: An Introduction. In Drug and Alcohol Abuse: A Clinical Guide to Diagnosis and Treatment. Edited by Schuckit MA: Springer Science+Business Media; 1989. 
Figure 1. HeLa cells grown in tissue culture and exposed to $50 \mathrm{mM}$ ethanol have altered mitochondrial ultrastructure. Panel 1, ultrastructure of a control HeLa cell at 10,000x. Panel 2 - 6, ultrastructure of HeLa cells obtained from cells treated with $50 \mathrm{mM}$ ethanol for $24 \mathrm{~h}$. Panels 2 and 3, 12,500x; Panels 4 and 5, 25,200x; Panel 6, 5,000x. M, mitochondria; N, nucleus; HM, hypertrophied mitochondria; RC, ruptured and reduced mitochondrial cristae; FF, disrupted mitochondrial fusion and fission or ethanol induced membrane hemifusion or both. All samples were stained with uranyl acetate and lead citrate and the transmission electron microscope was operated at $80 \mathrm{kV}$ (Materials and methods).

Figure 2. Effect of ethanol on Mitosis, Apoptotic Morphology, and Irregular Shaped Cells. There was not a statistically significant difference in the percentage of mitotic cells in treated versus control cells. Mitosis was $67 \%$ higher in the alcohol treatment with a p value of 0.019 . The effect of ethanol on apoptotic morphology was found to be statistically significant with a $\mathrm{p}$ value of 0.0014 . However, ethanol treatment was found to decrease the occurrence of apoptotic morphology by $\sim 60 \%$. This is the only variable that had fewer instances in the alcohol treatment, only about $2.6 \%$ occurrence compared to $6.1 \%$ in the control. The percentage of irregular cells was increased by about 2.6-fold in cells treated with ethanol as compared to controls. For ease of data visualization, proportion values from Table 1 were converted to percent $(\%)$.

Figure 3. Effect of ethanol on nuclei and nucleoli in HeLa cells. Ethanol was found to significantly affect the characteristics of multiple nuclei ( $\mathrm{p}$ value $=0.0012)$, indented nuclei $(\mathrm{p}$ value $<0.001)$, and multiple nucleoli $(\mathrm{p}<0.001)$. In all characteristics the percentage or 
proportion with alcohol was significatively higher than in the control treatment. For ease of data visualization, proportion values were converted to percent (\%).

Figure 4. Effect of ethanol treatment on mitochondria. Highly significant differences between the percentages of control and alcohol treatments were found for the characteristics of big mitochondria $(\mathrm{p}<0.001)$, ruptured mitochondria $(\mathrm{p}<0.001)$, and ruptured cristae $(\mathrm{p}<0.001)$. The percentages of cells with big mitochondria, ruptured mitochondria, and ruptured cristae were found to be increased by more than 2-fold after ethanol treatment as compared to controls. For ease of data visualization, proportion values were converted to percent (\%).

Figure 5. Ultrastructure of mitochondria obtained from HeLa cell culture treated with $\mathbf{5 0}$ mM ethanol for 24 hours. Most of the mitochondria are hypertrophied and have ruptured cristae (Arrows) or reduced mitochondrial cristae. Several mitochondria have irregular cristae arrangement. Several mitochondria show fusion-fission (FF). Stained with uranyl acetate and lead citrate. X74,800 Taken at $80 \mathrm{kV}$. Scale bar 500 nanometer. 
Figure 1
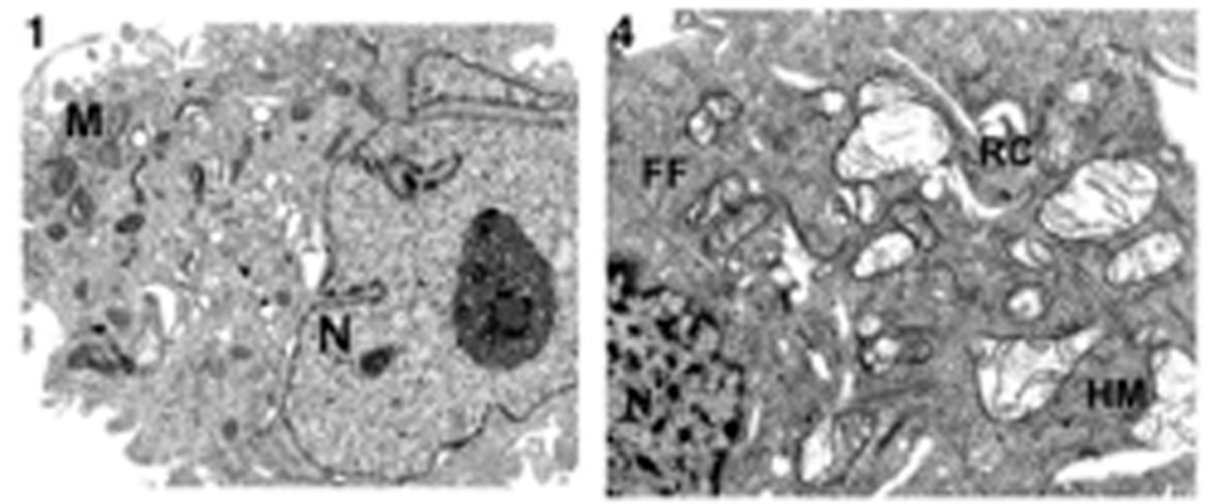

\section{2}
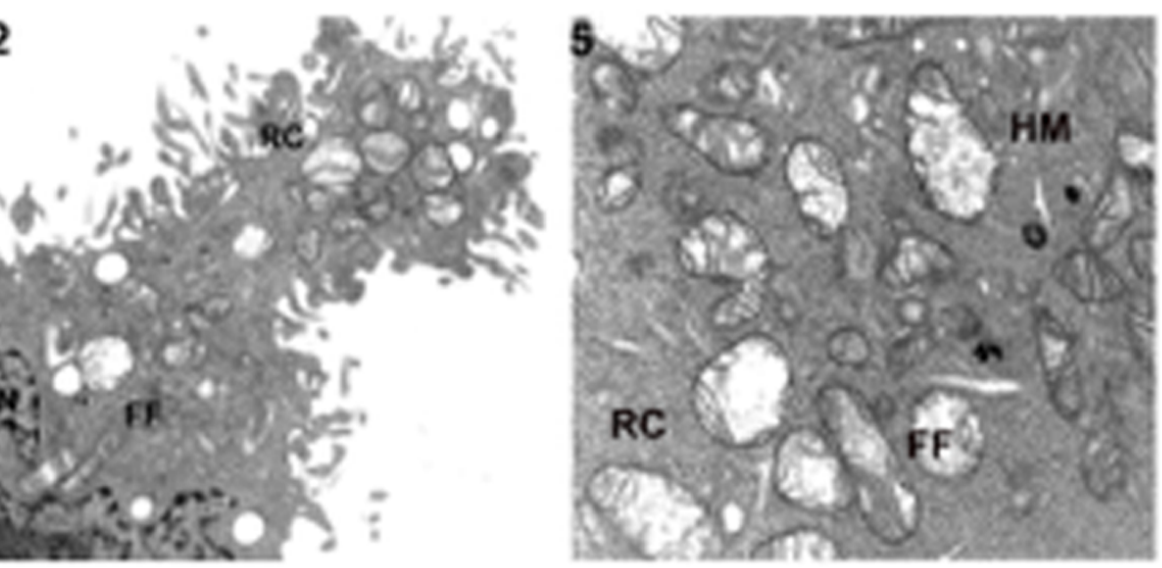

3
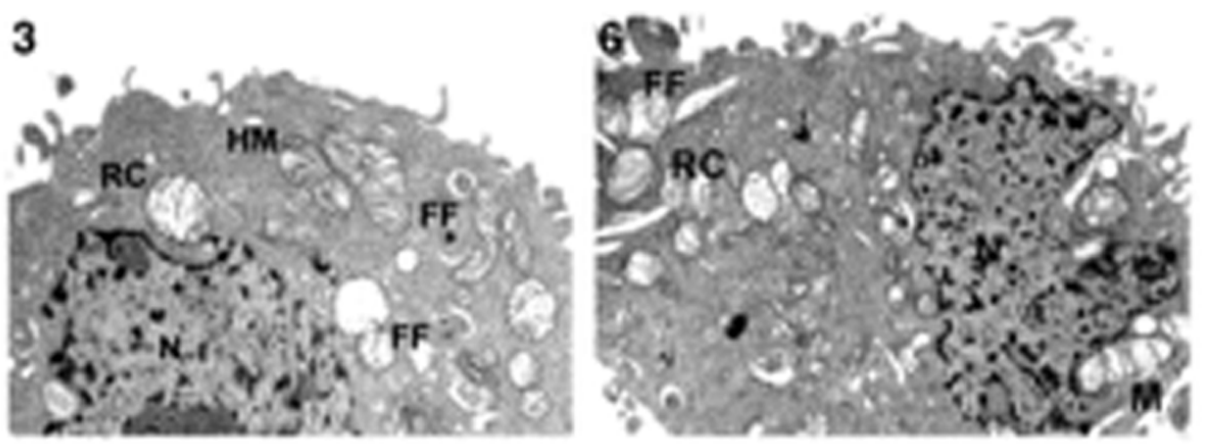
Figure 2

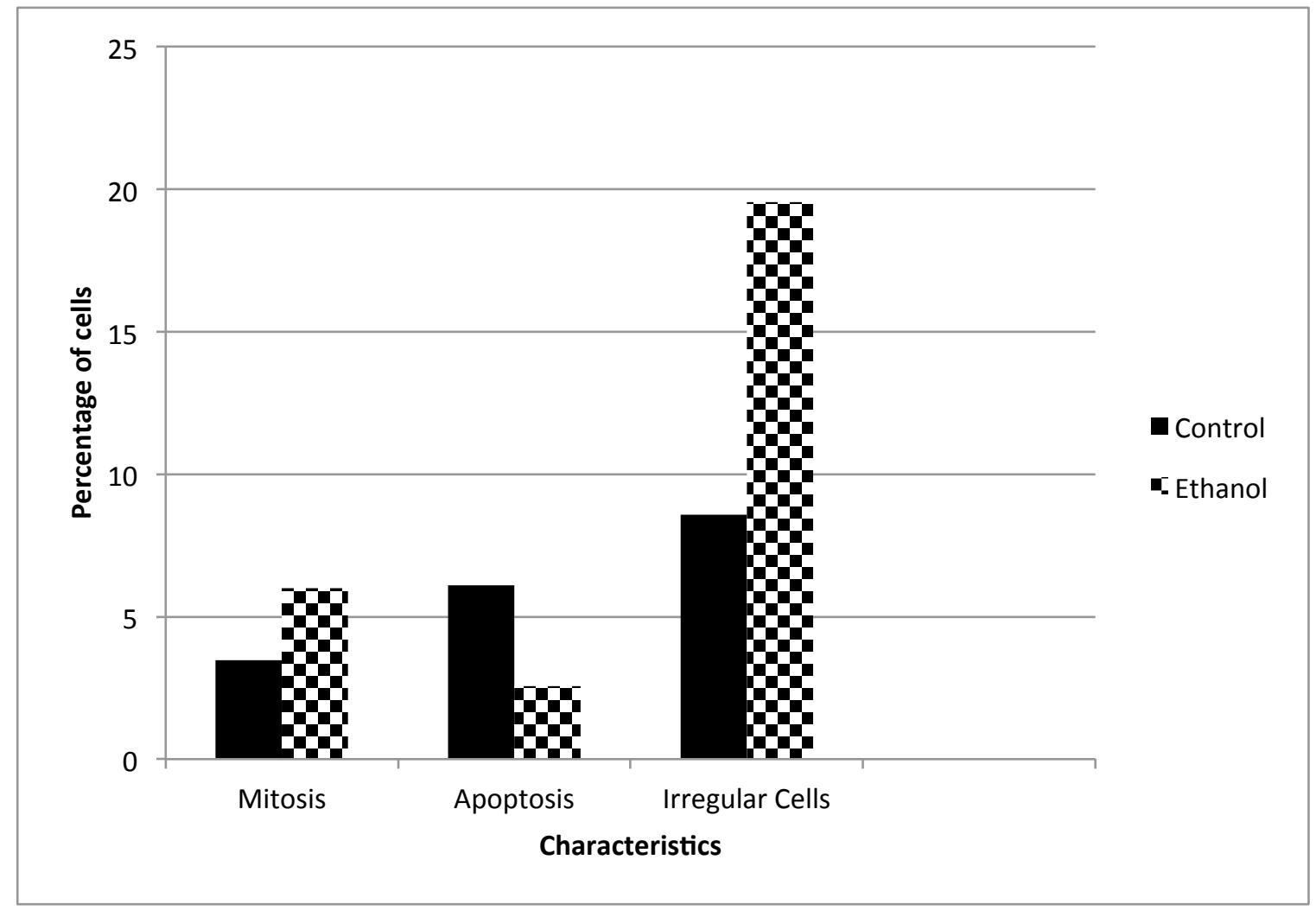


Figure 3

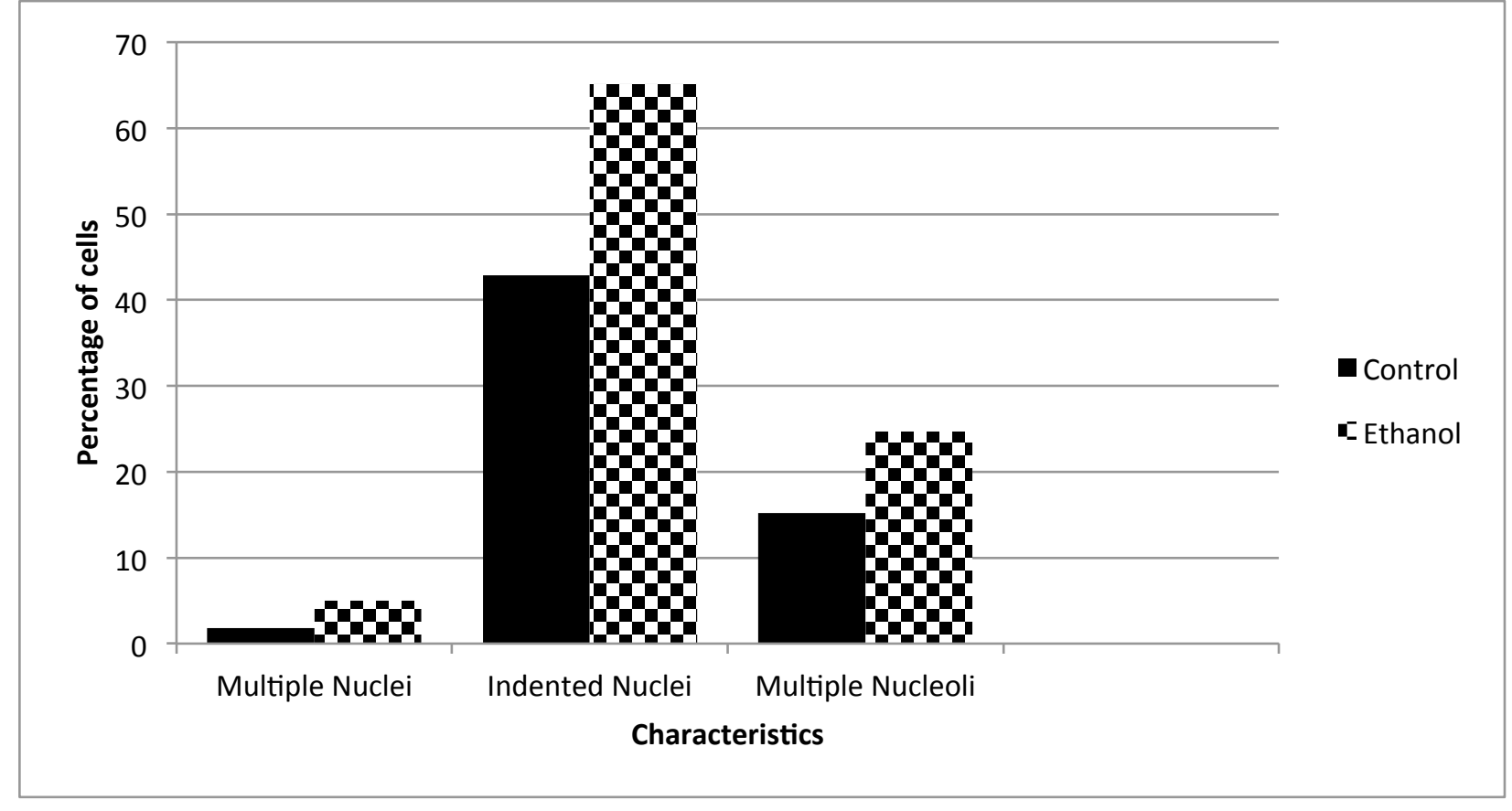


Figure 4

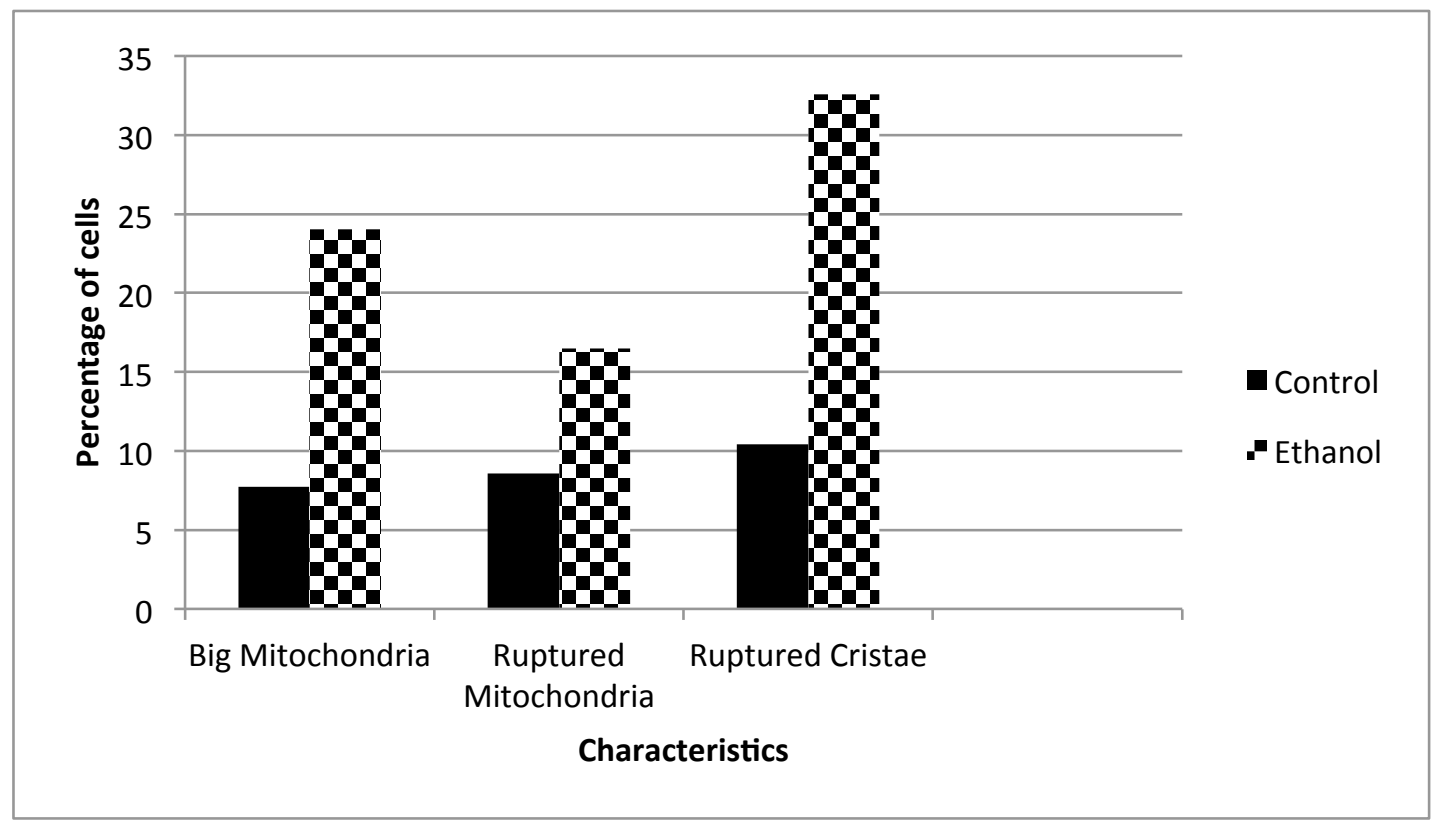




\section{Figure 5}

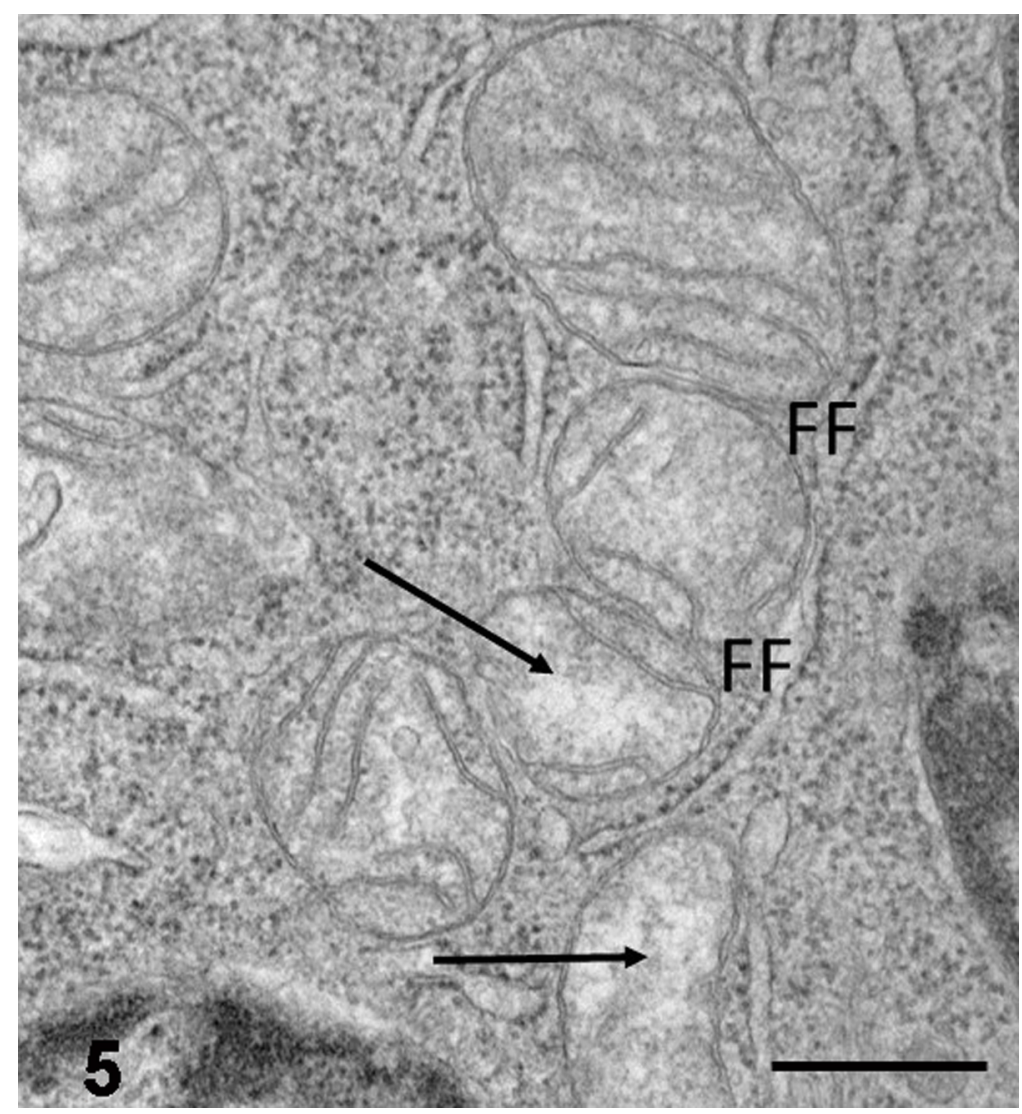


Table 1. Summary statistics for the effect of ethanol treatment on the ultrastructure of HeLa cells.

\begin{tabular}{|c|c|c|c|c|c|c|c|}
\hline Type & Treatment & Proportion & Lower & Upper & Test Statistic & p-value & Odds Ratio \\
\hline \multirow[t]{2}{*}{ Mitosis } & Alcohol & 0.0600343 & 0.0346908 & 0.085368 & \multirow[t]{2}{*}{2.065183} & \multirow[t]{2}{*}{0.0194528} & \multirow[t]{2}{*}{1.7791971} \\
\hline & Control & 0.0346535 & 0.0155142 & 0.0537927 & & & \\
\hline \multirow{2}{*}{$\begin{array}{l}\text { Apoptotic } \\
\text { Morphology }\end{array}$} & Alcohol & 0.025728988 & 0.008837698 & 0.042613721 & \multirow[t]{2}{*}{-2.97774714} & \multirow[t]{2}{*}{0.001451877} & \multirow[t]{2}{*}{0.406119147} \\
\hline & Control & 0.061056106 & 0.036001134 & 0.086111077 & & & \\
\hline \multirow[t]{2}{*}{ Irregular Cell } & Alcohol & 0.195540309 & 0.15734949 & 0.233731128 & \multirow[t]{2}{*}{5.457602158} & \multirow[t]{2}{*}{$2.41304 \mathrm{E}-08$} & \multirow[t]{2}{*}{2.589634246} \\
\hline & Control & 0.085808581 & 0.056500089 & 0.115117073 & & & \\
\hline \multirow[t]{2}{*}{ Multi Nuclei } & Alcohol & 0.04974271 & 0.026547575 & 0.072928841 & \multirow[t]{2}{*}{3.020184233} & \multirow[t]{2}{*}{0.001263105} & \multirow[t]{2}{*}{2.831473581} \\
\hline & Control & 0.018151815 & 0.004181965 & 0.032121665 & & & \\
\hline \multirow{2}{*}{$\begin{array}{l}\text { Indented } \\
\text { Nuclei }\end{array}$} & Alcohol & 0.651801029 & 0.600975391 & 0.702606937 & \multirow[t]{2}{*}{7.702273058} & \multirow[t]{2}{*}{$6.68334 \mathrm{E}-15$} & \multirow[t]{2}{*}{2.491095112} \\
\hline & Control & 0.429042904 & 0.377251028 & 0.480834781 & & & \\
\hline \multirow{2}{*}{$\begin{array}{c}\text { Multi } \\
\text { Nucleoli }\end{array}$} & Alcohol & 0.246998285 & 0.200987829 & 0.292990879 & \multirow[t]{2}{*}{4.11357031} & \multirow[t]{2}{*}{$1.94793 \mathrm{E}-05$} & \multirow[t]{2}{*}{1.832623552} \\
\hline & Control & 0.151815182 & 0.114264969 & 0.189365394 & & & \\
\hline \multirow{2}{*}{$\begin{array}{c}\text { Big } \\
\text { Mitochondria }\end{array}$} & Alcohol & 0.240137 & 0.194564 & 0.285693 & \multirow[t]{2}{*}{7.697905} & \multirow[t]{2}{*}{$6.92 \mathrm{E}-15$} & \multirow[t]{2}{*}{3.758705} \\
\hline & Control & 0.077558 & 0.049568 & 0.105547 & & & \\
\hline \multirow{2}{*}{$\begin{array}{c}\text { Ruptured } \\
\text { Mitochondria }\end{array}$} & Alcohol & 0.164665523 & 0.125097612 & 0.204218074 & \multirow[t]{2}{*}{4.117610166} & \multirow[t]{2}{*}{ 1.91411E-05 } & \multirow[t]{2}{*}{2.100142158} \\
\hline & Control & 0.085808581 & 0.056500089 & 0.115117073 & & & \\
\hline \multirow{2}{*}{$\begin{array}{l}\text { Ruptured } \\
\text { Cristae }\end{array}$} & Alcohol & 0.325901 & 0.275895 & 0.375886 & \multirow[t]{2}{*}{9.347579} & \multirow[t]{2}{*}{$4.48 \mathrm{E}-21$} & \multirow[t]{2}{*}{4.16697} \\
\hline & Control & 0.10396 & 0.072022 & 0.135898 & & & \\
\hline
\end{tabular}

